\title{
WHAT MOVES THE LABOR FORCE PARTICIPATION RATE?
}

\author{
DAVID H. BERNSTEIN
}

\begin{abstract}
The seasonally adjusted civilian labor force participation rate, the sum of employed and unemployed persons as a percentage of the civilian non-institutional population, is analysed in the general to specific modelling framework with a saturating set of step indicators from January 1977 through June 2018. The results indicate that, ceteris paribus, the rise in the ratio of women to men in the labor force in addition to positive demographic movements can largely account for the rise in the labor force participation rate up to January 2000. Subsequently, the aging population helps to explain the decline. Recessions play a transitory role.
\end{abstract}

\section{InTRODUCTION}

The seasonally adjusted civilian labor force participation rate (LFPR) climbed to a high of 67.3 percent in Jan-2000 from a low of 58.1 percent in Dec-1954. The large surge in participation beginning in the middle of the 1960s is attributed to women entering the labor market, changes in demographics, and the increased retirement age (Hotchkiss \& Rios-Avila 2013, Bullard 2014). After this historic climb, The Dot-com Crash, The Great Recession, and the retirement of the baby boomers are associated with a reversal resulting in a subsequent low in the LFPR of 62.4 percent in Sept-2015 (Aaronson, Davis \& Hu 2012, Aaronson, Cajner, Fallick, Galbis-Reig, Smith \& Wascher 2014, Bullard 2014). Movements in the LFPR continue to puzzle economists, and should be better understood.

Despite improvements in the labor market since The Great Recession, including the unemployment rate and the quantity of nonfarm payroll jobs, the LFPR has yet to recover to its Jan-2000 level. Figure 1, in conjunction with the recent political interest in the LFPR motivate this papers title: what moves the labor force participation rate? In other words:

UNIVERSITY OF MIAMI

Date: October 8, 2018.

Key words and phrases. Labor force participation rate, general to specific modelling, step indicator saturation.

David H. Bernstein, Department of Economics, University of Miami e-mail: dbernstein@bus.miami.edu Regressions were run in R version 3.4.4 (2018-03-15). I am grateful to Bent Nielsen, Manuel Santos and David L. Kelly for helpful comments at various stages of this research. I am also grateful to have attended Professor Hendry's advanced econometrics lectures in modelling and forecasting at Oxford University, for whom this special issue is named. All errors are mine alone. 
which economic, technological, and/or demographic factors best explain movements in the LFPR? Furthermore, given the rapidly aging populations across the world (and especially in Japan and Europe), the aforementioned questions are increasingly relevant.

Government forecasts of unemployment benefits, and aggregate variables such as GDP and the unemployment rate may be influenced by the LFPR. Correct forecasts for unemployment benefits are essential in budget planning. Additionally, monetary policy is explicitly linked to the overall strength of the labor market. Hence, though the Federal Reserve Bank (Fed) may not have all the tools necessary to influence the LFPR, the Fed and policy experts can still (potentially) influence policy makers via policy recommendations.

FiguRE 1. Seasonally Adjusted, Civilian Labor Force Participation Rate

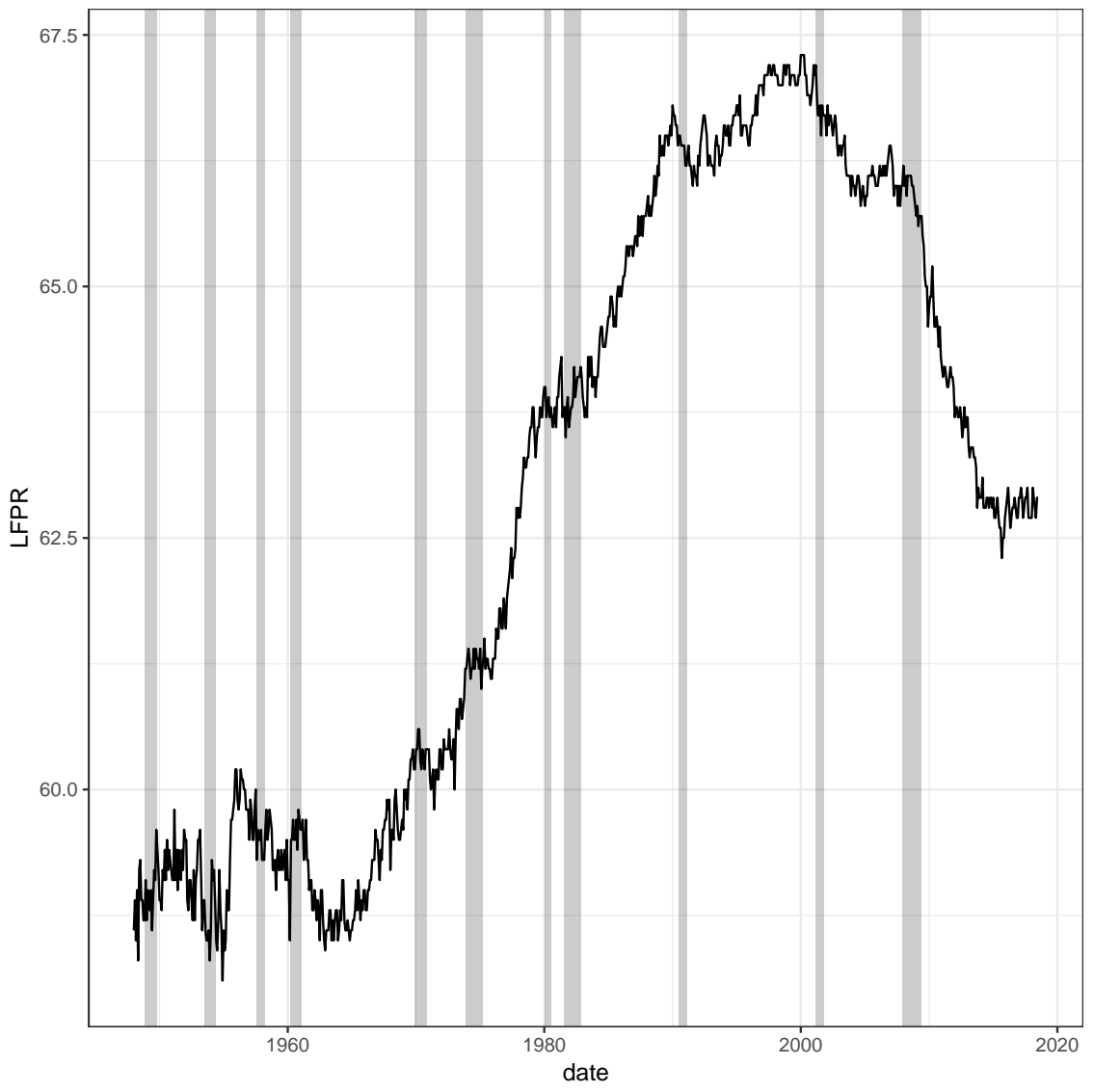

Much of the recent interest in the LFPR has centered around the impact of the Great Recession on the LFPR. $]^{1}$ For example, Hotchkiss \& Rios-Avila (2013) attribute the large

${ }^{1}$ Technological progress manifested in new capital goods may also impact the LFPR as well as the labor share (Plant, Santos \& Sayed 2017, Karabarbounis \& Neiman 2014). Plant et al. (2017) attribute the large surge in the labor share from 1995 through 2000 to the large capital spending in that period, but stipulate 
decline in the LFPR during the Great Recession entirely to cyclical factors. Using Current Population Survey data from 2005-2007 and from 2010-2012, Hotchkiss \& Rios-Avila (2013) argue that had behavior not changed after the Great Recession, that the LFPR would have declined even further. Conversely, Zandweghe (2012) only attribute half of the decline to cyclical factors, whereas Aaronson et al. (2012) attribute nearly half of the decline to the aging population. Given the great divergence in academic opinion and the recent national interest in the LFPR, this research area may benefit from further inquiry.

This study utilizes macroeconomic variables to answer the question posed in the paper's title. The highly correlated nature of macroeconomic variables necessitates a model selection procedure that is less vulnerable to dependencies between and/or among variables. Given the manifold competing theories ascribed to the LFRP, general to specific (Gets) modelling

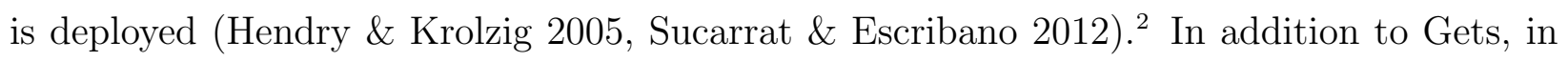
order to capture location shifts, step indicator saturation (SIS) is performed prior to model selection with all candidate variables included as suggested by Castle, Doornik, Hendry \& Pretis (2015). Castle et al. (2015) demonstrate via Monte Carlo simulations that the least absolute shrinkage and selection operator (LASSO) and the least-angle regression (LARS) work well for a single step, but are less reliable than SIS in the presence of multiple breaks. Visual examination of the LFPR data suggest that multiple breaks may be present.

This paper is organized as follows. Section 2 outlines the empirical strategy employed and presents a small monte carlo simulation, Section 3 describes the data sample, while Section 4 presents the findings. Section 5 concludes, and additional results may be found in Appendix A.

\section{Empirical Strategy}

The Gets procedure begins with a general unrestricted model (GUM) of the form

$$
y_{t}=\beta_{0}+\beta^{\prime} x_{t}+\epsilon_{t},
$$

where $x_{t}$ is a matrix of candidate variables and $\beta$ is a vector of coefficients. The GUM contains all candidate variables ascribed to a particular dependent variable from theory, institutional knowledge, data availability and historical events (Hendry \& Krolzig 2005). Furthermore, the GUM is assumed to contain a nested local data generating process (LDGP) which is not

that it has been declining since the late 1970s. The tech bubble could also partially explain the less dramatic surge in the LFPR during the same period, and overall decline after Jan-2000.

${ }^{2}$ Gets is also sometimes refereed to as the "LSE approach to econometrics" or "Hendry's methodology" after Professor Sir David F. Hendry. 
the same as the true data generating process (DGP), but is considered to be a statistically valid characterization of the true DGP (Sucarrat 2010, Hendry 2011).

Though it is sometimes claimed (incorrectly) that Gets is data mining, it is not. A forceful rejection of that claim, and discussion of valid criticisms of the LSE approach can be found in Hoover \& Perez (1999) and in many works by David Hendry (Hendry \& Krolzig 2005). Hoover \& Perez (1999) use the data set of Lovell (1983) to demonstrate the ability of Gets to successfully recover the true DGP, when known. Gets presently utilizes backwards elimination, goodness-of-fit measures, parsimonious encompassing and single/multiple hypothesis testing in order to find relevant variables, dynamic relationships and non-linearities. Furthermore, the Gets procedure ultimately yields a parsimonious, and statistically valid model, whereas other data mining tools are not designed to do this. Many improvements to the Gets algorithm and implementation have occurred since 1999, and are currently available via Autometrics (Doornik \& Hendry 2013) and the gets package (Pretis, Reade \& Sucarrat 2016) in R. The implementation of Gets herein is carried out via the gets package in $R$

SIS is the process of adding in indicators of the form $\iota_{1}^{\prime}=(1,1,1, \cdots, 1,1,1)=\beta_{0}, \iota_{2}^{\prime}=$ $(0,1,1 \cdots, 1,1,1), \ldots \iota_{T}^{\prime}=(0,0,0 \cdots, 0,0,1)$ to the standard regression model (Equation 1$)$

$$
y_{t}=\beta_{0}+\beta^{\prime} x_{t}+\sum_{j=1}^{T-1} \delta_{j} 1_{(t \geq j)}+\epsilon_{t},
$$

in order to find statistically significant breaks in equation 2 4 SIS is feasible computationally in Equation 2 because current software can easily handle more candidate variables $(\mathrm{N})$ than observations (T) (Doornik 2009, Pretis et al. 2016). The procedure for SIS is a simple three step procedure when the null of no steps is correct. First estimate Equation 2 with T/2 indicators and record significant indicators (specified at a significance level $\alpha$ ), then repeat the first step with the other half of indicators, and finally estimate Equation 2 with all candidate significant steps and retain any steps that remain. On average, assuming there are no breaks in the true DGP, if the significance level is chosen to be $\alpha=1 / T$, then one step indicator will remain after the procedure, and hence-one degree of freedom is lost on average.

2.1. Monte Carlo Findings. To demonstrate the reliability of SIS in gets to identify one significant break, a Monte Carlo simulation is presented. Assuming a DGP of the form

\footnotetext{
${ }^{3}$ To see Gets applied to atmospheric $\mathrm{CO}_{2}$ levels, see Hendry \& Pretis (2013).

${ }^{4}$ The split-half one-cut procedure for SIS is analogous to the procedure for impulse-indicator saturation (IIS), although the analysis for each method is different (Castle et al. 2015).
} 


$$
y_{t}=\beta_{0}+1_{(t>T / 2)} \cdot q+\epsilon_{t},
$$

with $R=1,000$ replications, $T=500, q \in\{0, .1, .2, \ldots, 4.9,5\}, \beta_{0}=10$ and $\epsilon=\mathcal{N}(0, \rho)$ for $\rho \in\{0.1,0.3,0.5,0.7,1.0,1.2,1.5\}$ the following evidence bears consideration as to the finite sample properties of the isat function within the gets package.

Figure 2. Gauge

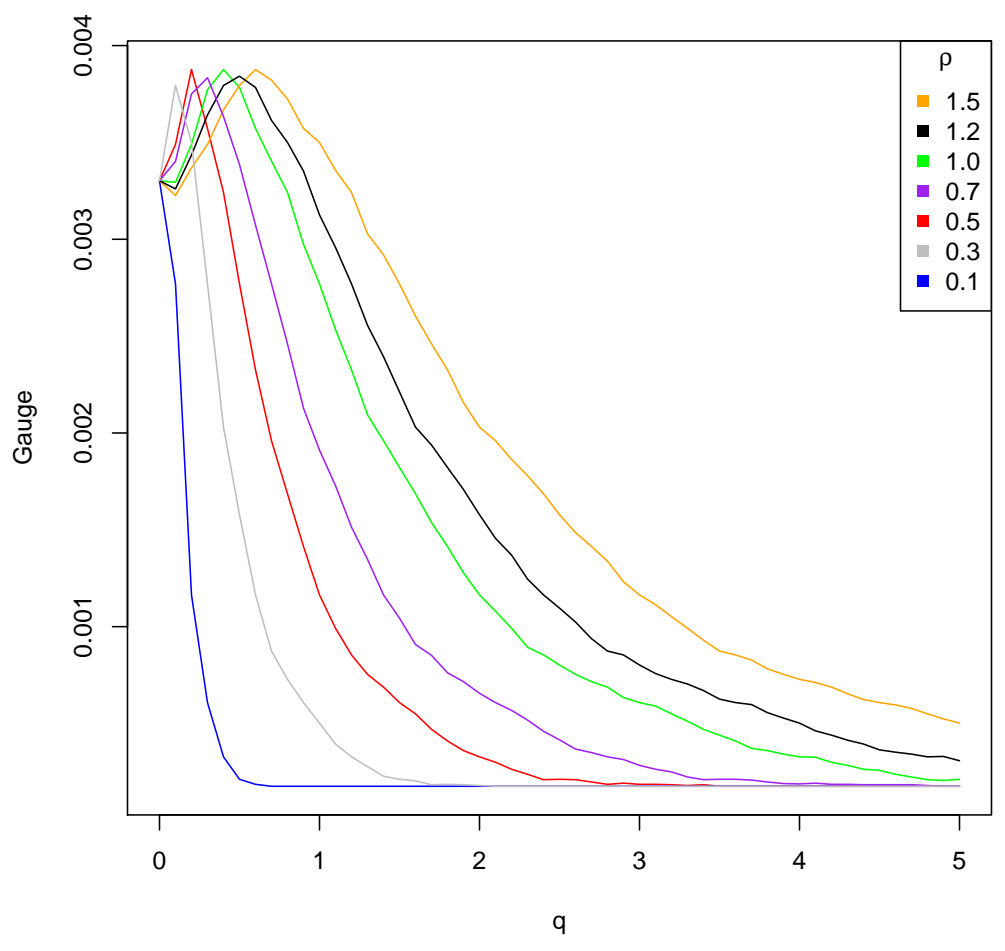

The gauge describes the percentage of irrelevant variables retained, whereas the potency describes the percentage of relevant variables retained. Empirically, one can define the average gauge for each $(q, \rho)$ pair as satisfying:

$$
\text { avg. gauge }=(R T)^{-1} \sum_{r=1}^{R} \sum_{t=1}^{T}\left(1-v_{r t}\right),
$$

where $v_{r t}$ equals zero if an erroneous variable was selected at time $t$ in replication $r$, and one otherwise (Johansen \& Nielsen 2016). As an example, when $q \geq 3.5$, and $\rho=0.5, v_{r t}$ was equal to zero exactly 88 times, over all 1,000 replications. This can be seen in figure 2 where 
6

the curve corresponding to $\rho=0.5$ asymptotes. More generally, figure 2 demonstrates that the gauge increases from the one model without a step for small values of $q$, but then falls quickly thereafter as might be expected as $q$ increases. Furthermore, the gauge is decreasing in $\rho$, as might be expected. In the null situation where $q=0$, the avg. gauge across different values of $\rho$ was equal to 0.0033 as compared to $0.002=1 / 500=1 / T$, as is suggested by theory.

Figure 3. Potency

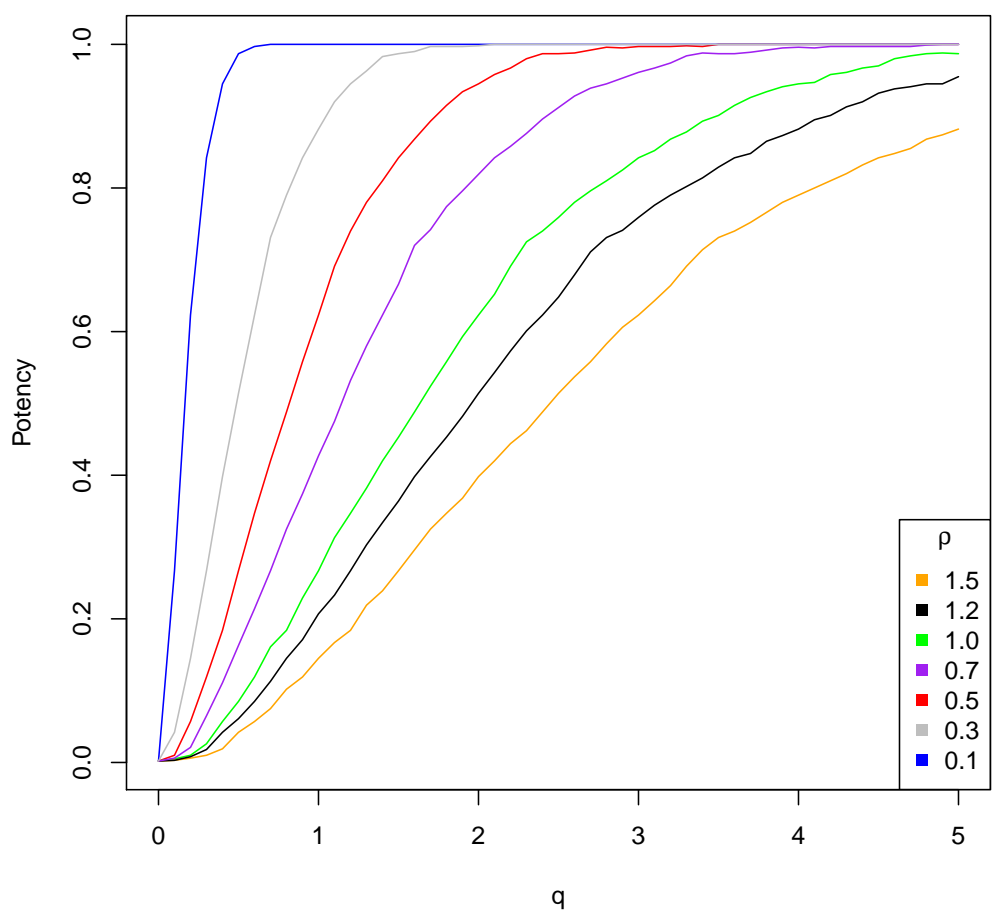

The average potency for the significant step, can be defined as:

$$
\text { avg. potency }=(R)^{-1} \sum_{r=1}^{R} 1_{r,(251)},
$$

where $1_{r,(251)}$ is an indicator that is 1 when the step was correctly identified in replication $\mathrm{r}$ and zero otherwise. As an example, when $\rho=0.5,1_{r,(251)}$ was equal to one twice when $q=0$, and was non-zero in every regression model for $q \geq 3.5$. The latter can be seen as an asymptote to unity. Figure 3 demonstrates that potency increases in $q$ and decreases in $\rho$, as one would expect. 


\section{DATA}

The Federal Reserve Economic Data (FRED) data, presented in Table 1, span Jan-1977

TABle 1. Variable Definitions and Summary Statistics: 1-1977 to 6-2018

\begin{tabular}{cllll}
\hline \hline Num. & Codes & Descriptions & Mean & S.Dev \\
\hline 1 & CIVPART & Labor Force Participation Rate & 65.17 & 1.52 \\
2 & FEDFUNDS & Eff. Federal Funds Rate & 5.02 & 4.1 \\
3 & USREC & NBER based Recession & 0.11 & 0.32 \\
4 & PSAVERT & Personal Saving Rate & 7.54 & 2.32 \\
5 & INDPRO & Industrial Production Index & 79.2 & 20.07 \\
6 & IPMINE & Industrial Production: Mining & 93.52 & 8.54 \\
7 & CPIBOOKS & CPI: Educational books and supplies & 296.96 & 192.83 \\
8 & WAP25T54 & Working Age Population: Aged 25-54 & 53.73 & 2.74 \\
9 & WAP55T64 & Working Age Population: Aged 55-64 & 12.89 & 1.87 \\
10 & WAP15T24 & Working Age Population: Aged 15-24 & 17.49 & 2.28 \\
11 & REALINC & Real Disposable Personal Income & 10.33 & 0.22 \\
12 & SFTP & San Francisco Tech Pulse & 51.74 & 30.83 \\
13 & WOMEN/MEN & Civilian Labor Force Ratio of Women to Men & 83.43 & 5.15 \\
14 & BLACK & Black Percentage of Labor Force & 11.2 & 0.64 \\
15 & HISP & Hispanic Percentage of Labor Force & 10.68 & 3.87 \\
16 & MANEMP & Manufacturing Employees & 14.02 & 4.29 \\
\hline
\end{tabular}

to Jun-2018 $!^{5}$ A spherical representation of the correlation matrix is presented in Figure 4. and an ordinary correlation matrix can be found in Appendix A, Table 5$]^{6}$ From Figure 4. the grouping of variables on the unit sphere indicates highly correlated variables. For example, the LFPR (1) is highly correlated (.98) with the working age population aged 2554 (8). This high correlation helps to motivate the impact of demography on the LFPR (Aaronson et al. 2012, Aaronson et al. 2014). Additionally, the grouping of variables 5 and 11 (correlation .98) provides a link between real income and industrial production, and the NBER based recession indicator (3) rate is not highly correlated with any other variables presented.

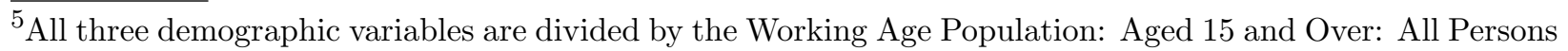
for the United States (LFWATTTTUSM647S) and multiplied by 100 to give a percentage. WOMEN/MEN is $100 *$ LNS11000002/LNS11000001), or the Labor Force level of women over men. BLACK (HISP) is the percentage of the labor force that is Black (Hispanic). The data listed are all available from FRED Economic Data online at https://fred.stlouisfed.org. A graphic of the data appears in Appendix A Figure 7.

${ }^{6}$ There exists an isomorphism between the correlation matrix and points on the unit hypersphere (Falissard 1996). A spherical representation of the correlation matrix helps to visualize the correlations between/among many variables.
} 
Figure 4. Spherical Representation of Correlation Matrix
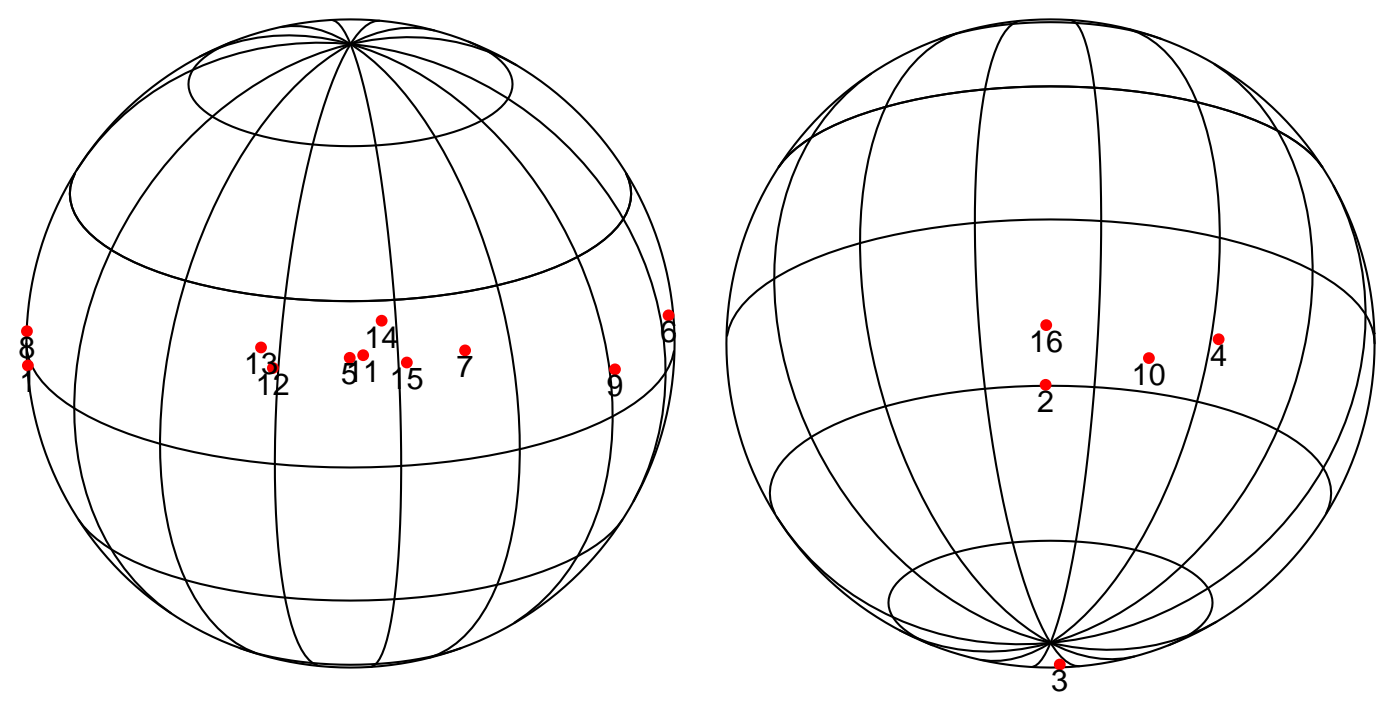

The selection of variables herein was made based on both data availability and on the emphasis of particular variables within the existing literature. The data used in this paper are unique in that aggregate macroeconomic variables are utilized rather than population survey type data as are emphasized in the existing literature. As the existing literature has largely focused on survey data, some decisions had to be made regarding the adequate representation of aggregate variables. For example, educational attainment, usually embodied by the number of years of education a survey participant reports, is captured by an educational consumer price index for books and supplies. Given the persistent upward trend, CPIBOOKS does a good job of capturing the relatively recent emphasis on education. The benefit of 
using the Gets framework is that if new variables become available, it is straightforward to add them into the GUM, and computationally fast to re-estimate the model. 7$]$

\section{Results}

The GUM is formulated from all variables in Table 1 plus two lags of each variable, squared terms, the interaction between all variables with the recession indicator (denoted by an $R$ before the variable), and five significant steps. 8

Figure 5. Contribution of demographics and autoregressive terms over time
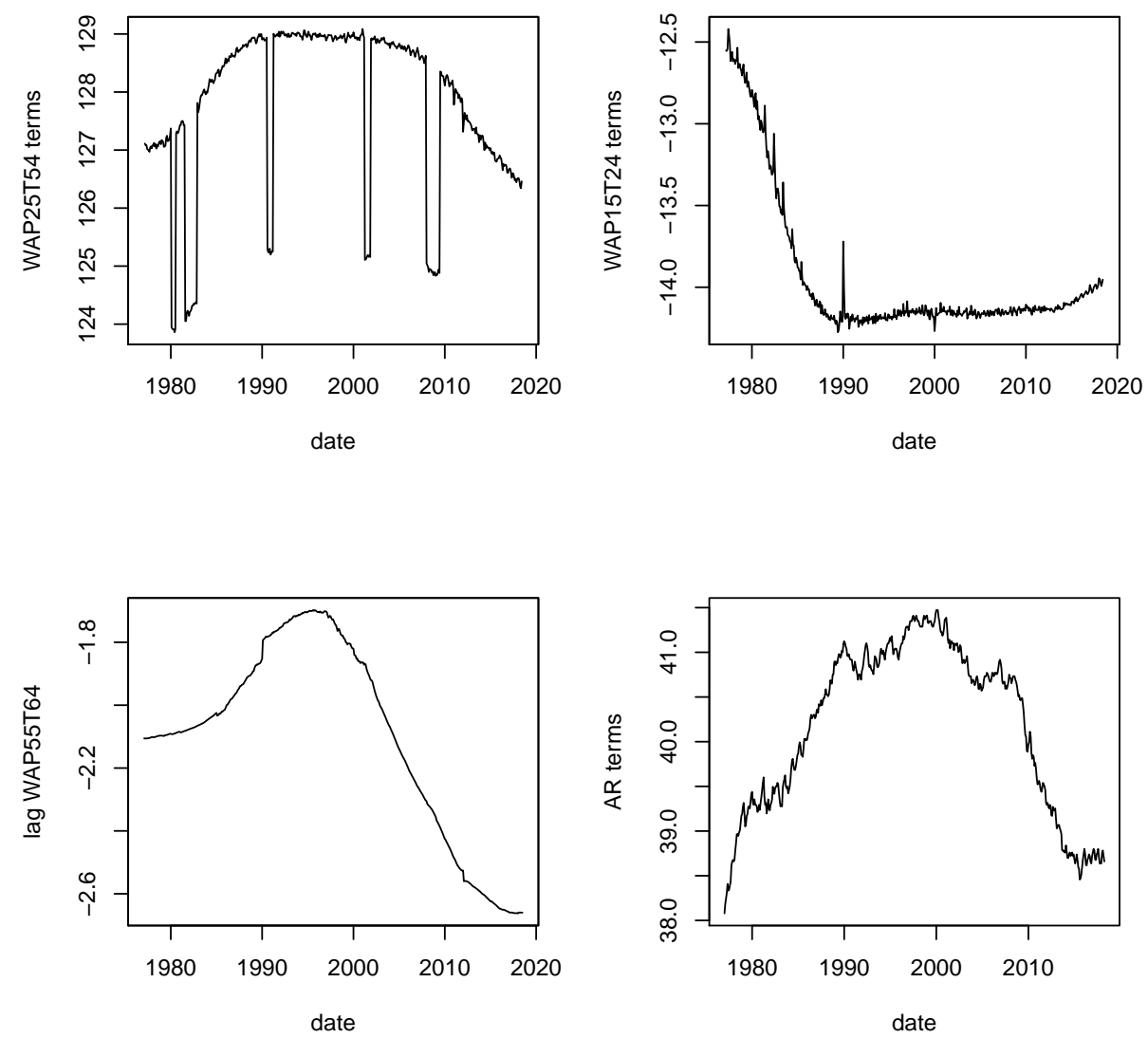

Figures 5, 6 and 8 (in Appendix A) present each variable multiplied by their corresponding coefficients to demonstrate the impact of each variable over time. For variables such as

${ }^{7}$ The run time for the main model herein took just over one minute.

${ }^{8}$ Several variable manipulations could not be included in the GUM due to multicollinearity. All code to replicate these results are available upon request. 
the WAP25T54, that appears in many different forms in the final model, the terms were appropriately multiplied, then added together.

Figure 6. Contribution of women/men over time

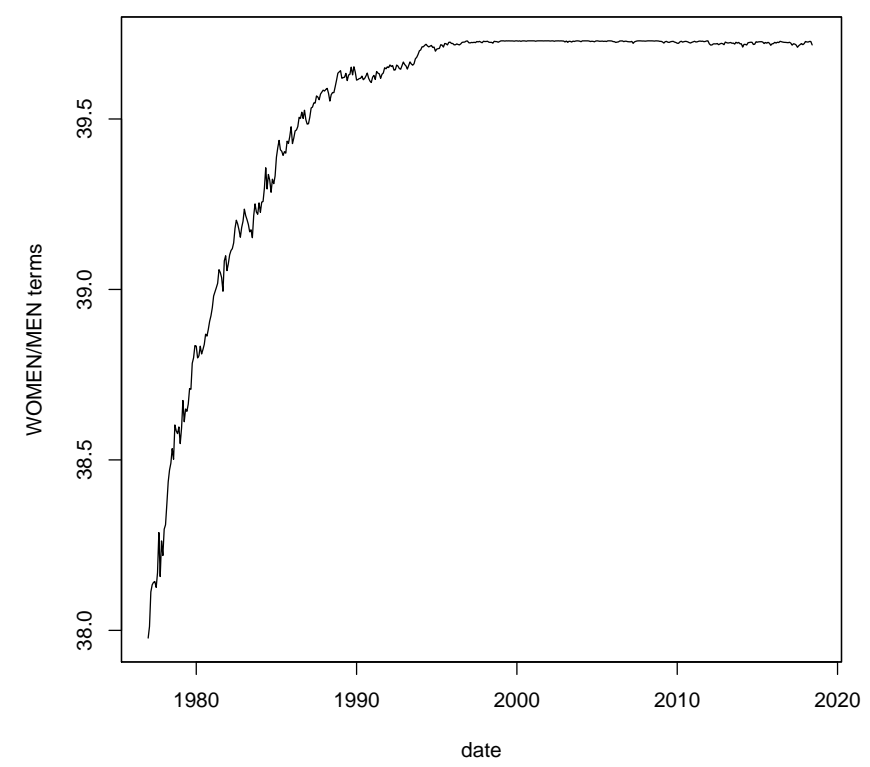

The GUM and specific mean equation pass all diagnostic tests required by the Gets algorithm in Pretis et al. (2016), and the interpretations of the specific mean equation coefficients are ordinary excluding all REALINC variables in which a one percent increase in real disposable income leads to a $\frac{x}{100}$ increase in the LFPR, as this variable was transformed via the natural logarithm due to its large relative size. The specific mean equation can be found in Table 3 in Appendix A. Table 4 in Appendix A presents diagnostic tests on this equation.

Table 2 provides the changes in each variable over three distinct periods over which the LFPR has had large movements. The first period is from March-1977 to Jan-2000, the second period is from Jan-2000 to Sept-2015, while current final period is from Sept-2015 to Jun-2018.

In the three time periods considered, just over 60 percent of the LFPR can be explained by the LFPR in the previous two months. A simple autoregressive model with two lags and a constant gives an $R^{2}$ of 0.991 with a log-likelihood $(T=496)$ of 272.4 . Beyond this persistent effect, from 1977(3) to 2000(1), other things equal, just over 30 percent of the rise in LFPR can be explained by the increase in the ratio of women to men in the labor force. In this first period, the large increase in the ratio of women to men in the labor force was partially offset 
TABLE 2. Percentage change in variables over three distinct periods

\begin{tabular}{llrrr}
\hline & Variable & $1977(3)-2000(1)$ & $2000(1)-2015(9)$ & $2015(9)-2018(6)$ \\
\hline 1 & CIVPART & 5.3 & -5 & 0.6 \\
2 & FEDFUNDS & 0.76 & -5.31 & 1.68 \\
3 & USREC & 0 & 0 & 0 \\
4 & PSAVERT & -5.1 & 2.3 & -0.9 \\
5 & INDPRO & 46.04 & 9.56 & 3.99 \\
6 & IPMINE & -4.91 & 24.39 & 11.06 \\
7 & CPIBOOKS & 217.6 & 379.53 & 55.01 \\
8 & WAP25T54 & 6.88 & -7.22 & -0.67 \\
9 & WAP55T64 & -1.64 & 4.92 & 0.12 \\
10 & WAP15T24 & -6.58 & -0.79 & -0.59 \\
11 & REALINC & 0.48 & 0.23 & 0.04 \\
12 & SFTP & 97.1 & -25.74 & 12.27 \\
13 & WOMEN/MEN & 17.48 & 0.95 & 0.6 \\
14 & BLACK & 1.63 & 0.73 & 0.22 \\
15 & HISP & 7.25 & 4.97 & 0.9 \\
16 & MANEMP & -8.85 & -4.51 & -0.14 \\
\hline
\end{tabular}

by a moderate decrease in the percentage of 15-24 year old people in the overall economy, as well as a variety of other factors that can be seen in figure 8 in Appendix A. From 2000(1) to 2015(9), the demographic aging of the population, as seen by the working age population aged 15 to 24 and 25 to 54 accounts for the majority of the decline in the LFPR.

The role of recessions is particularly intriguing visually. Those most impacted by recessions are the WAP25T54, manufacturing employees and Hispanic workers, via interaction terms. The REALINC helps to mitigate recessions, but only by a small amount. Figures 5 and 8 demonstrate the impact that recessions have on these groups of individuals.

\section{Concluding Remarks}

The findings in this paper are especially corroborated by Bullard (2014) who writes that, "Many, including me, might reason that a good demographic model combined with more women in the labor force during the 1970s, 1980s, and 1990s could explain a very large fraction of the hump-shaped movements in aggregate labor force participation over the postwar era." Bullard (2014) further supports the view that cyclical factors play a minor role in the LFPR. This works finds that while recessions can be very damaging to the LFPR, their impact is transitory. Moving forward, given that the ratio of women to men in the labor force is fairly large (0.88 in June 2018) and close to the models implied optimal mix of 0.87, the WAP25T54 will likely be the biggest determinant of the LFPR moving forward. Similarly, 
the ability of workers to participate in the labor force past 55 years of age, as seen in figure 5 and the miscellaneous terms in figure 8 will be interesting to watch over the next 40 years.

\section{REFERENCES}

Aaronson, D., Davis, J. \& Hu, L. (2012), 'Explaining the decline in the u.s. labor force participation rate', Chicago Fed Letter (296).

Aaronson, S., Cajner, T., Fallick, B., Galbis-Reig, F., Smith, C. \& Wascher, W. (2014), 'Labor force participation: Recent developments and future prospects', Brookings Papers on Economic Activity $\mathbf{4 5}(2$ (Fall)), 197-275.

Bullard, J. (2014), 'The rise and fall of labor force participation in the united states', Federal Reserve Bank of St. Louis Review Q1, 1-12.

Castle, J., Doornik, J. A., Hendry, D. F. \& Pretis, F. (2015), 'Detecting location shifts during model selection by step-indicator saturation', Econometrics 3, 240-264.

Doornik, J. A. (2009), Autometrics, in 'in Honour of David F. Hendry', University Press, pp. 88-121.

Doornik, J. A. \& Hendry, D. F. (2013), Empirical Econometric Modelling Using PcGive 14: Volume I, Timberlake Consultants Press, London.

Falissard, B. (1996), 'A spherical representation of a correlation matrix', Journal of Classification 13(2), 267280.

Hendry, D. F. (2011), 'Empirical Economic Model Discovery and Theory Evaluation', Rationality, Markets and Morals $\mathbf{2}(46)$.

Hendry, D. F. \& Krolzig, H.-M. (2005), 'The properties of automatic gets modelling', The Economic Journal 115(502), C32-C61.

URL: http://dx.doi.org/10.1111/j.0013-0133.2005.00979.x

Hendry, D. F. \& Pretis, F. (2013), Anthropogenic influences on atmospheric co2, in 'Handbook on Energy and Climate Change', Edward Elgar Publishing, chapter 12, pp. 287-326.

Hoover, K. D. \& Perez, S. J. (1999), 'Data mining reconsidered: encompassing and the general-to-specific approach to specification search', The Econometrics Journal 2(2), 167-191.

URL: http://www.jstor.org/stable/23115013

Hotchkiss, J. \& Rios-Avila, F. (2013), 'Identifying factors behind the decline in the u.s. labor force participation rate', Business and Economic Research 3(1).

Johansen, S. \& Nielsen, B. (2016), 'Asymptotic theory of outlier detection algorithms for linear time series regression models', Scandinavian Journal of Statistics 43(2), 321-348.

URL: https://onlinelibrary.wiley.com/doi/abs/10.1111/sjos.12174

Karabarbounis, L. \& Neiman, B. (2014), 'The global decline of the labor share', The Quarterly Journal of Economics 129(1), 61-103.

Lovell, M. C. (1983), 'Data mining', The Review of Economics and Statistics 65(1), 1-12.

URL: http://www.jstor.org/stable/1924403

Plant, R., Santos, M. S. \& Sayed, T. (2017), Computerization, Composition of Employment, and Structure of Wages, Working Papers 2017-09, University of Miami, Department of Economics. 
Pretis, F., Reade, J. \& Sucarrat, G. (2016), General-to-Specific (GETS) Modelling And Indicator Saturation With The R Package Gets, Economics Series Working Papers 794, University of Oxford, Department of Economics.

Sucarrat, G. (2010), 'Econometric reduction theory and philosophy', Journal of Economic Methodology $\mathbf{1 7}(1), 53-75$.

Sucarrat, G. \& Escribano, A. (2012), 'Automated model selection in finance: General-to-specific modelling of the mean and volatility specifications', Oxford Bulletin of Economics and Statistics 74(5), 716-735.

Zandweghe, W. V. (2012), 'Interpreting the recent decline in labor force participation', Economic Review (Q I), 5-34. 
Appendix A. Appendix

TABLE 3. Specific mean equation

\begin{tabular}{|c|c|c|c|c|}
\hline & coef & std.error & t-stat & p-value \\
\hline$\beta_{0}$ & -419.08 & 120.16 & -3.49 & 0.00 \\
\hline$L F P R_{t-1}$ & 0.40 & 0.04 & 9.56 & 0.00 \\
\hline$L F P R_{t-2}$ & 0.22 & 0.04 & 5.57 & 0.00 \\
\hline INDPRO & -0.05 & 0.02 & -2.65 & 0.01 \\
\hline IPMINE & 0.04 & 0.01 & 2.79 & 0.01 \\
\hline WAP25T54 & 5.22 & 0.81 & 6.42 & 0.00 \\
\hline WAP15T24 & -1.13 & 0.41 & -2.76 & 0.01 \\
\hline REALINC & 55.54 & 22.98 & 2.42 & 0.02 \\
\hline WOMEN/MEN & 0.91 & 0.14 & 6.33 & 0.00 \\
\hline BLACK & 0.27 & 0.06 & 4.32 & 0.00 \\
\hline HISP & -0.63 & 0.10 & -6.48 & 0.00 \\
\hline INDPRO $^{2}$ & 0.00 & 0.00 & 2.68 & 0.01 \\
\hline IPMINE $^{2}$ & -0.00 & 0.00 & -3.05 & 0.00 \\
\hline WAP25T $54^{2}$ & -0.04 & 0.01 & -5.18 & 0.00 \\
\hline WAP15T $24^{2}$ & 0.05 & 0.01 & 4.42 & 0.00 \\
\hline REALINC $^{2}$ & -2.63 & 1.10 & -2.38 & 0.02 \\
\hline WOMEN/MEN ${ }^{2}$ & -0.01 & 0.00 & -6.06 & 0.00 \\
\hline $\mathrm{HISP}^{2}$ & 0.03 & 0.01 & 5.96 & 0.00 \\
\hline FEDFUNDS $_{t-1}$ & 0.02 & 0.00 & 4.96 & 0.00 \\
\hline WAP25T54 $4_{t-1}$ & -0.38 & 0.14 & -2.74 & 0.01 \\
\hline WAP $55 \mathrm{~T} 64_{t-1}$ & -0.16 & 0.07 & -2.50 & 0.01 \\
\hline WAP15T24 $4_{t-1}$ & -0.34 & 0.11 & -2.95 & 0.00 \\
\hline WAP25T54 $4_{t-2}$ & -0.32 & 0.10 & -3.09 & 0.00 \\
\hline WAP15T24 $4_{t-2}$ & -0.20 & 0.09 & -2.22 & 0.03 \\
\hline $1_{\mathrm{REC}} * \mathrm{WAP} 25 \mathrm{~T} 54$ & -0.07 & 0.01 & -5.11 & 0.00 \\
\hline $1_{\mathrm{REC}} * \mathrm{REALINC}$ & 0.74 & 0.17 & 4.22 & 0.00 \\
\hline $1_{\mathrm{REC}} * \mathrm{HISP}$ & -0.19 & 0.06 & -3.00 & 0.00 \\
\hline $1_{\mathrm{REC}} * \mathrm{MANEMP}$ & -0.14 & 0.04 & -3.15 & 0.00 \\
\hline sis: Jun 1981 & -0.76 & 0.11 & -6.73 & 0.00 \\
\hline sis: Jul 1981 & 0.54 & 0.12 & 4.45 & 0.00 \\
\hline sis: Jun 1982 & -0.50 & 0.09 & -5.50 & 0.00 \\
\hline sis: Aug 1982 & 0.46 & 0.09 & 4.93 & 0.00 \\
\hline sis: Sep 1996 & 0.17 & 0.04 & 4.05 & 0.00 \\
\hline SE of reg. & 0.115 & & & \\
\hline$R^{2}$ & 0.994 & & & \\
\hline Log-lik. $(\mathrm{n}=491)$ & 378.542 & & & \\
\hline
\end{tabular}

Labels: 1) Labor Force Participation Rate, 2) Eff. Federal Funds Rate, 3) NBER based Recession, 4) Personal Saving Rate, 5) Industrial Production Index, 6) Industrial Production: 
TABLE 4. Diagnostic tests on the specific mean regression equation

\begin{tabular}{lrrr}
\hline & Chi-sq & df & p-value \\
\hline Ljung-Box AR(3) & 0.75 & 3.00 & 0.86 \\
Ljung-Box ARCH(1) & 0.46 & 1.00 & 0.50 \\
Jarque-Bera & 2.05 & 2.00 & 0.36 \\
\hline
\end{tabular}

TABLE 5. Correlations

\begin{tabular}{lrrrrrrrrrr}
\hline \hline & 1 & 2 & 3 & \multicolumn{1}{c}{4} & 5 & \multicolumn{1}{c}{6} & 7 & 8 & \multicolumn{1}{c}{9} & \multicolumn{1}{c}{10} \\
\hline 1 & 1.00 & 0.02 & 0.03 & -0.48 & 0.07 & -0.71 & -0.28 & 0.97 & -0.74 & -0.36 \\
2 & 0.02 & 1.00 & 0.19 & 0.60 & -0.78 & -0.02 & -0.80 & -0.03 & -0.47 & 0.78 \\
3 & 0.03 & 0.19 & 1.00 & 0.13 & -0.10 & -0.03 & -0.09 & -0.05 & 0.00 & 0.15 \\
4 & -0.48 & 0.60 & 0.13 & 1.00 & -0.80 & 0.32 & -0.54 & -0.42 & -0.11 & 0.77 \\
5 & 0.07 & -0.78 & -0.10 & -0.80 & 1.00 & 0.13 & 0.90 & 0.02 & 0.55 & -0.85 \\
6 & -0.71 & -0.02 & -0.03 & 0.32 & 0.13 & 1.00 & 0.40 & -0.68 & 0.56 & 0.02 \\
7 & -0.28 & -0.80 & -0.09 & -0.54 & 0.90 & 0.40 & 1.00 & -0.30 & 0.79 & -0.76 \\
8 & 0.97 & -0.03 & -0.05 & -0.42 & 0.02 & -0.68 & -0.30 & 1.00 & -0.80 & -0.37 \\
9 & -0.74 & -0.47 & 0.00 & -0.11 & 0.55 & 0.56 & 0.79 & -0.80 & 1.00 & -0.22 \\
10 & -0.36 & 0.78 & 0.15 & 0.77 & -0.85 & 0.02 & -0.76 & -0.37 & -0.22 & 1.00 \\
11 & 0.03 & -0.84 & -0.10 & -0.74 & 0.98 & 0.15 & 0.94 & 0.00 & 0.59 & -0.90 \\
12 & 0.28 & -0.67 & -0.08 & -0.84 & 0.94 & -0.03 & 0.74 & 0.23 & 0.32 & -0.84 \\
13 & 0.35 & -0.76 & -0.11 & -0.78 & 0.89 & -0.02 & 0.78 & 0.33 & 0.27 & -0.98 \\
14 & -0.01 & -0.79 & -0.17 & -0.64 & 0.91 & 0.31 & 0.92 & -0.02 & 0.53 & -0.90 \\
15 & -0.10 & -0.83 & -0.07 & -0.67 & 0.96 & 0.25 & 0.98 & -0.13 & 0.68 & -0.84 \\
16 & -0.05 & 0.85 & 0.08 & 0.74 & -0.96 & -0.11 & -0.93 & -0.02 & -0.57 & 0.91 \\
\hline \hline & 11 & 12 & 13 & 14 & 15 & 16 & & & & \\
\hline 1 & 0.03 & 0.28 & 0.35 & -0.01 & -0.10 & -0.05 & & & & \\
2 & -0.84 & -0.67 & -0.76 & -0.79 & -0.83 & 0.85 & & & & \\
3 & -0.10 & -0.08 & -0.11 & -0.17 & -0.07 & 0.08 & & & & \\
4 & -0.74 & -0.84 & -0.78 & -0.64 & -0.67 & 0.74 & & & & \\
5 & 0.98 & 0.94 & 0.89 & 0.91 & 0.96 & -0.96 & & & & \\
6 & 0.15 & -0.03 & -0.02 & 0.31 & 0.25 & -0.11 & & & & \\
7 & 0.94 & 0.74 & 0.78 & 0.92 & 0.98 & -0.93 & & & & \\
8 & 0.00 & 0.23 & 0.33 & -0.02 & -0.13 & -0.02 & & & & \\
9 & 0.59 & 0.32 & 0.27 & 0.53 & 0.68 & -0.57 & & & & \\
10 & -0.90 & -0.84 & -0.98 & -0.90 & -0.84 & 0.91 & & & & \\
11 & 1.00 & 0.89 & 0.92 & 0.94 & 0.99 & -0.99 & & & & \\
12 & 0.89 & 1.00 & 0.88 & 0.84 & 0.84 & -0.87 & & & & \\
13 & 0.92 & 0.88 & 1.00 & 0.90 & 0.87 & -0.93 & & & & \\
14 & 0.94 & 0.84 & 0.90 & 1.00 & 0.93 & -0.92 & & & & \\
15 & 0.99 & 0.84 & 0.87 & 0.93 & 1.00 & -0.98 & & & & \\
16 & -0.99 & -0.87 & -0.93 & -0.92 & -0.98 & 1.00 & & & & \\
\hline & & & & & & & & & & \\
\hline
\end{tabular}


FiguRe 7. Data Plots
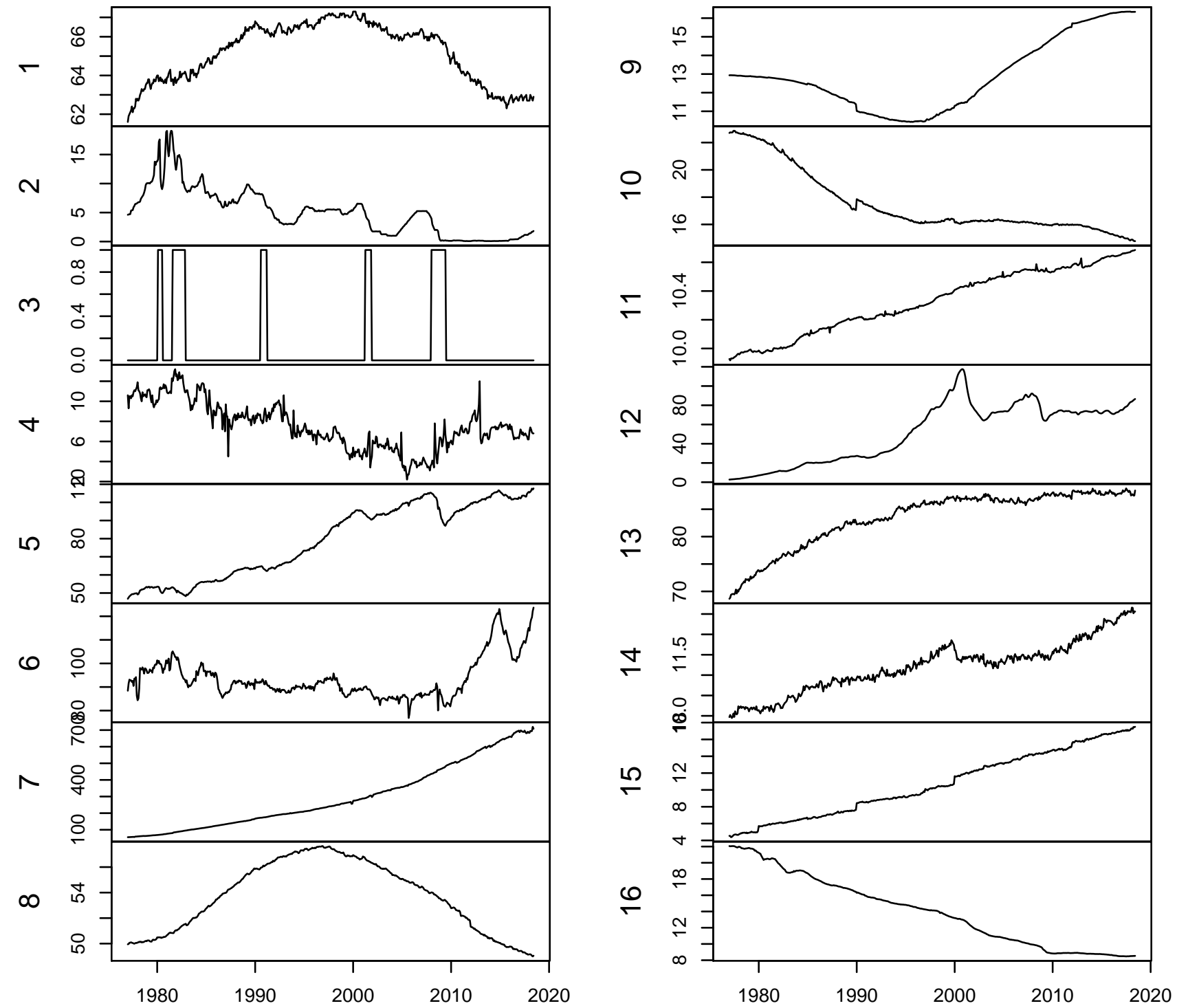

Mining, 7) CPI: Educational books and supplies, 8) Working Age Population: Aged 25-54, 9) Working Age Population: Aged 55-64, 10) Working Age Population: Aged 15-24, 11) Real Disposable Personal Income, 12) San Francisco Tech Pulse, 13) Civilian Labor Force Ratio of Women to Men, 14) Black Percentage of Labor Force, 15) Hispanic Percentage of Labor 
Force, 16) Manufacturing Employees.

FiguRE 8. Miscellaneous contributions over time
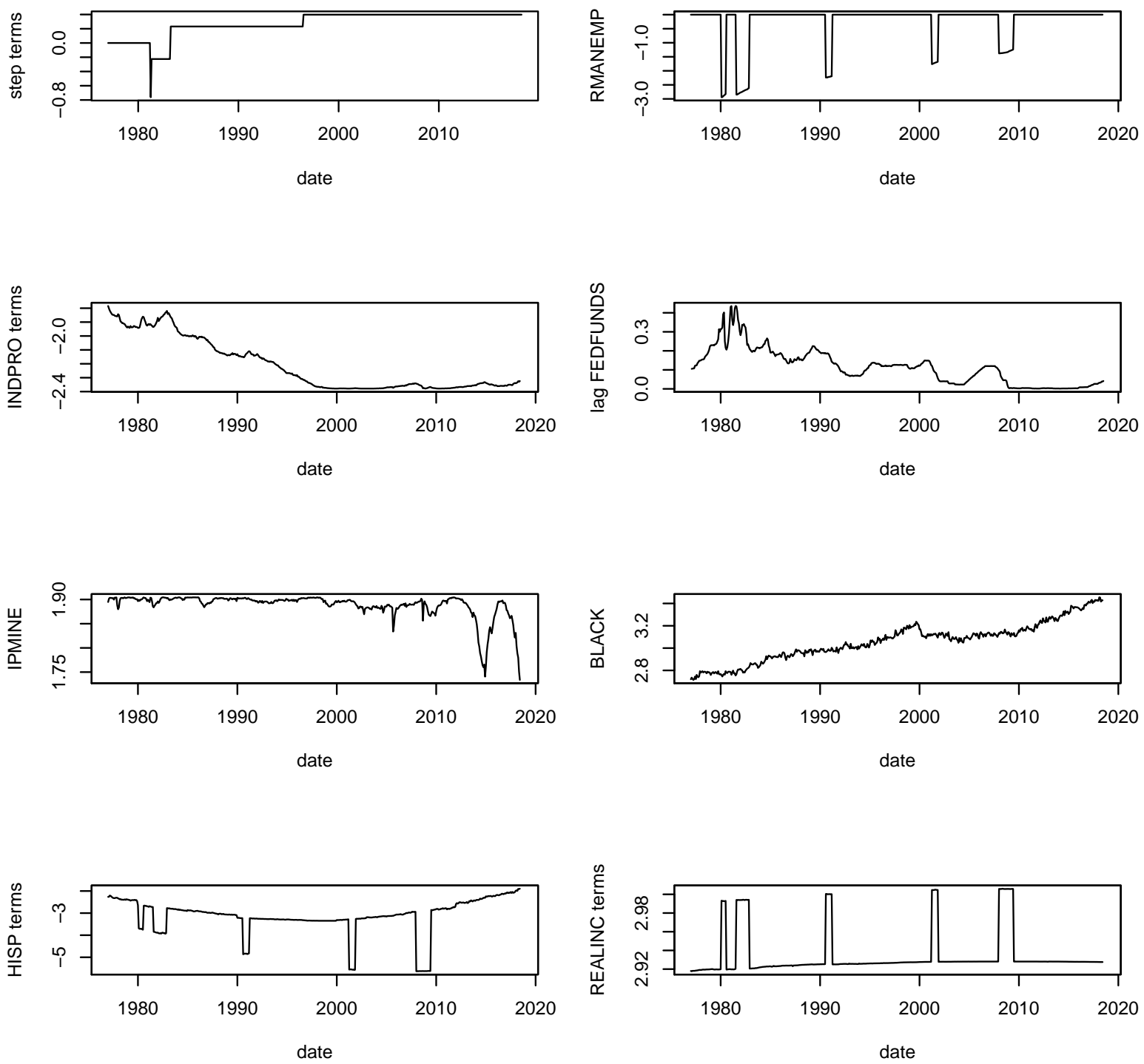